\title{
Hybridization of Cultural Identity of Indian Diaspora
}

\author{
Sakshi Kanchan, Puneet Chansauria \\ Post Graduate Student, Srishti Institute of Art, Design and Technology, Bangalore University, \\ 40/D Marilingiah Building 2nd Cross Rd Yelahanka New Town KHB Colony Bangalore Karnataka 560106 IN, 2nd Cross Rd, \\ Bengaluru, Karnataka 560064 \\ Post Graduate, Tata Institute of Social Sciences, Mumbai, \\ V.N. Purav Marg, Eden Gardens, Deonar, Mumbai, Maharashtra 400088
}

\begin{abstract}
A sense of belonging to a community, nation and culture is an integral part of a person's identity. It strongly influences an individual's self-perception, self-conception and a rationalised relation with nationality, ethnicity, religion, social class, generation, locality or any other kind of social group. Culture informs the identity irrespective to the causes of migration, for instance, culture remains a defining force in forced migrants i.e. the ones impacted by the push factors as climate disasters, refugee crisis, poverty, wars etc. and it is of equal persuasion for the ones who willingly went for better livelihood and job opportunities abroad. In both cases the immigrants undergo acculturation and therefore they imbibe the cultural aspects of another country. But the ways in which the diaspora negotiate with the sustainability of their ethnicities, identities and cultures while simultaneously undergoing the process of acculturation are intriguing. These complex processes form the subject of the research.

It is difficult to ascertain the extent of a person's need for support in sustaining his cultural spectrum, we rather intend to measurably explore whether culture needs to be preserved and sustained at all given that the blending of the cultural spectrum of two different regions has already taken place. And we need to substantiate our findings by exploring nuances and narratives and through secondary research.

If an individual or community successfully transmits the cultural identity through practices to other people or coming generations, then it can be taken as the sustenance of the cultural identity. Our intention here is to give a platform for them to connect with the sense of belongingness and for safeguarding the cultural identity of the diaspora.

We have tried to avoid the colloquial underdone while using the word culture and have rather used the etymological definition which is 'to cultivate'- It has basically originated from the French word- 'culture', which translates into cultivating or idea of promoting growth. The word growth here signifies the true meaning of care which is conserving. By extension, it can be said that culture grows when intangibles are taken care of and conserved.
\end{abstract}

Index terms: Migration, Identity, Culture, Ethnicity, Diaspora, Acculturation, Memory, Oral History

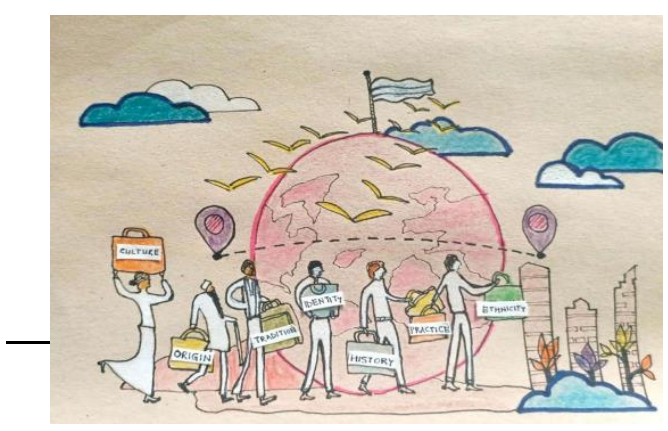

\section{In between Origin and Adaptation}

Fig.01 - Visual Abstract representing migrants taking the elements of cultural identity with them, wherever they go, signifying the relative keywords.

Migration - movement from one place to another, from one cultural dominion to another. Practically, movement between nation states constitute migration.

Identity - is whatever a person predominantly identifies with whether it is a country, ethnicity or religion, etc.

Culture - is a composite of ideas, social behavior and customs. It is intricately connected with ethnicity too.

Ethnicity - is based on a group (called an ethnic group) that normally has similar traits, such as a common language, common heritage, and cultural similarities within the group. Other variables that play a role in determining ethnicity, though not in all cases, include a geographical connection to a particular place, common foods and diets, and perhaps a common faith. ${ }^{1}$

Diaspora - the dispersion or spread of any people from their original homeland.

Acculturation - Acculturation is a process in which an individual adopts, acquires and adjusts to a new cultural environment.

Memory - the remembrance of the experiences in the past. In context of this research, memory may be significant while holding on to the cultural roots.

Oral History -the collection and study of historical information using tape recordings of interviews with people having personal knowledge of past events.

\section{AREA OF IMPACT AND KEY ACTORS}

In today's era of globalisation, mass migration, and acculturation, the idea for sustenance of the cultural identity, ethnicity is a proliferating thought. Even understanding their importance and influence in one's life is crucial yet again as it defines the identity of the individual or even the community.

India is unique for the magnitude of her diversities in terms of languages and regions, religions and sects, castes and subcastes, rural and urban, food and style of dress, which are also reflected by her diasporic communities. There are diasporic communities formed on the basis of linguistic or regional identities such as Punjabis, Gujaratis, Sindhis, 
Tamils, Malayalee and Telugus. Global organizations such as Global Organization of People of Indian Origin (GOPIO), World Telugu Federation (WTF), and World Punjabi Organization (WPO), have recently emerged to preserve and promote the identities and cultures of Indians, uniting transnationally and the global Indian diaspora. ${ }^{2}$ These communities widely undergo acculturation but acculturation coincides with deeply entrenched original traditions and belief systems. The article examines the influence of elements of culture in their life. The level of observance varies significantly within the diaspora, while some are culturally conservative others are markedly casual, but in all the cases the most common thing is the sense of belongingness. It may be with the language, or with the cuisine, or festivals and history, which is as diversified as the country's culture.

If the idea of support is to provide a platform for the diaspora to connect with each other and form a space for shared memories and experiences, and later build up the collective social memory then the impact is huge and perpetual and key actors are the migrants, both forced and opportunists of the diasporic community.

\section{CRITICAL INQUIRY AND RESEARCH QUESTION}

This project proposes to present, in practice, that Indian diaspora follow to sustain the hybridisation of their cultural identity after migration, which itself is a culture. Culture can also be defined as an intangible part of identity. The research sets out to find the role of ethnicity, hybridisation of culture, based on various elements such as migration, acculturation of Indian Diaspora and how can they (Indian Diaspora) be connected with their intangible cultural landscape.

The research question focuses on the different elements of culture that we can talk about w.r.t Indian Diaspora and the ways in which they develop their unified global identity as Indian Diaspora. Finally, it aims at exploring nuances, collecting variety of narratives in order to understand the importance of culture in the life of Indian diaspora.

We believe the research question also can be used as a base for identifying the role of Heritage Institution's towards Diasporic Culture. To explore the process that sustain the culture despite the cultural gap, and understanding the transition or even transformation through Oral History which, furthermore, can be archived in order to substantiate the process of conserving, preserving ad sustaining. The process of gathering and evaluating information apart from doing a survey with 25 people (primary research) and through the comments and views of the 25 people in secondary research (literature reviews) we essentially collected narratives which signify one's resolution that culture is an essential part of one's identity.

\section{SYNTHESISING DATA: ASSETS AND INSIGHTS}

It is essential to understand the literal meaning of the word diaspora for understanding the significance of culture in the life of an Indian diaspora. The term diaspora comes from an ancient Greek word meaning "to scatter about." And that's exactly what the people of a diaspora do - they scatter from their homeland to places across the globe, spreading their culture in the process. As the statement is based on the assumption that the person is connected with his/her homeland though it isn't possible for him/her to be sociopolitically and economically connected (for example he doesn't vote) but yes socio- culturally nationality is a part of cultural identity of the person.

That is why the concept of diaspora is focused upon in the questions which have been raised through interviews, taken as a part of the research method. In today's global world and free movement our personal identities are changing so, questions like where is my "home" and what is my "identity" are becoming increasingly relevant in one's life. In recent times, more and more diasporic communities visit their homelands, perhaps to revive their identities.

The critical inquiry suggests the limitations of the research method arising out of the inherent subjectivity of the topic. Many people, by virtue of being a significant part of the community, have various, diversified experiences and thought process towards sustaining their ethnicity and, originality.

\section{METHODOLOGY}

The project comprises of the two main elements - the process how the research has been done and the representation of the transcripts of the personal beliefs of the interviewee. From the word conservation, we mean the intangible culture which is basically the practice of following certain things in certain ways with an underlying belief system that can be passed from one generation to the next. For instance, the middle aged Indian parents who went and settled abroad for better economic opportunities and work day and night want their young children to know about their culture. To follow it or not to is their children's choice. But to share the knowledge can be a method of conserving the intangible culture.

Indians have a long history of migration to different parts of the world. Colonial migration that began in the 1830 s to the British, French and Dutch colonies and post-colonial migration to industrially developed countries constitute two important phases of creation of Indian diaspora. With a population of more than 20 million spread across the globe, the reimagining of territoriality is done through an evocative call to feel the love and affection of mother India. ${ }^{3}$

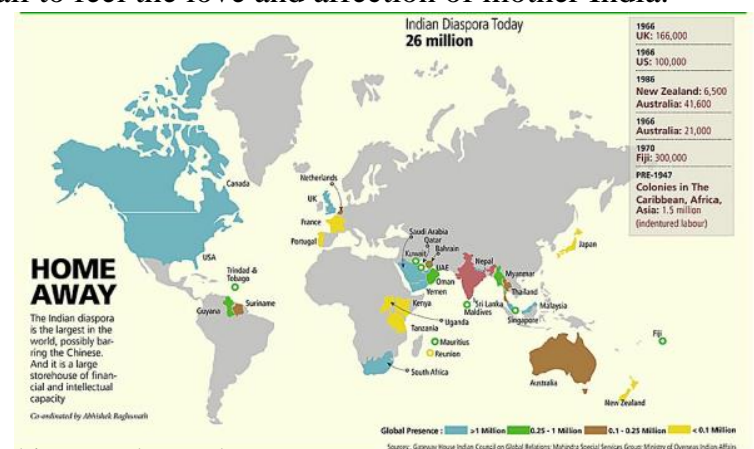

This map shows the current numbers of people of Indian Diaspora, spread across the world.

Source: Ministry of overseas Indian affair. 
Currently, UNESCO and other Global organizations such as Global Organization of People of Indian Origin (GOPIO), World Telugu Federation (WTF), and World Punjabi Organization (WPO), have emerged at the forefront to actively preserve and promote identities and cultures, uniting transnationally the diaspora. Therefore, this digest can be a manual, with various original transcripts of shared experiences from Indian Diaspora itself and can be published in a series available for all.

As the part of the research, to understand the elements of the culture was really important. And to know about the influence of each in the restricted time span was challenging. That is why the most significant and predominant elements are taken into consideration. The elements chosen for study are Languages, Foods, and Festivals, these three are not chosen out of the personal affinity but because they are the backbone to any culture. The individual reasons for selecting them are as follows-

Language- The most essential medium to express and transmit one's feelings, experiences and knowledge to future generation, besides performing art forms, is verbal communication and literature. Language plays an important role, when it come to the part of one's identity and culture. India being a heterogeneous cultural land, for every community, its language is a way to express their emotion, in spite of English being lingua franca. Other than the way of expression, a person inculcates a sense of belonging with the language. For example, the cultural humour, can only be understood by the people who relates with the culture which comprises of all the elements, among which the language is on the top of the list for obvious reasons.

Food- Food is another distinct part of culture and can be considered requirement and amenity for human life. But apart from the taste, and a sense of belonging of food with the culture and community cannot be disregarded. For instance, if we talk about India, Gujaratis, Punjabis, Tamilians, and other ethnicities have distinct cuisines and they tend to preserve it while experimenting with the cuisines of the host country. But as We said, apart from these essential qualities, Indian diaspora should also know about this cultural element in particular because of its medicinal qualities. Many spices are used as medicines.

Festivals- The easiest way to have a social gathering in and outside India is festivals. Indian festivals are famous not just for the congregations they inspire but for the collective celebration and festivities. Diwali, Holi, Christmas, Lori, Dassehra, Urs, Navratri, etc. are the festivals which have different folklores attached to them. These folklores constitute an important tradition which must be preserved by Indian diaspora.

\section{CONCLUSION- PROPOSED OUTPUT}

The output of the research includes illustrations and visuals articulating the narratives collected through secondary research which was interviewing.

The research and the framework was aimed at raising awareness regarding the restoration of cultural identity and understanding the process of hybridisation. The concept of the output, is to build a platform for diasporic community in order to connect with each other and share experiences, anecdotes and narratives, both visually and through literature. These can be compiled and published as compendium or digest. On platform thus created, diaspora can talk about food recipes, history of festivals, cultural jokes in different languages etc. It can also be developed as a digital platform which can later evolve into an organisation.

Attached Output link for Reference is given below: https://issuu.com/sakshikanchan/docs/output_digest_in_between_origin_an_07af53d88b30cf Kindly click here to find the document.

\section{BIBLIOGRAPHY}

Eilers, Christian. 2019. "What's The Difference?"." Ethnicity Vs. Nationality Vs. Race Vs. Heritage Vs. Culture - Verses (Dauntless Jaunter.). https://djaunter.com/enrich/.

Raghuram, Parvati and Sahoo,A.K. 2010. "Tracing an Indian Diaspora:contexts,Memories,Represntation." doi:10.4135/9788132100393.

Sahoo, Ajaya k. 2006. "Issues of Identity in the Indian Diaspora:A Tarnsnational Perspective." Perspective as Global Development and Technology 5: 81-98. doi:10.1163/156915006777354482.

\section{REFERENCES}

\section{JOURNAL ARTICLE}

[1] Ajaya Kumar Sahoo \& Dave Sangha (2010) Diaspora and cultural heritage: the case of Indians in Canada, Asian Ethnicity, 11:1, 8194, DOI: $10.1080 / 14631360903506786$

[2] Vinayak Chaturvedi (2018) From Oral History to Intellectual History (and the Unintended Autobiography), South Asia: Journal of South Asian Studies, 41:4, 846862, DOI: $10.1080 / 00856401.2018 .1514554$

\section{BOOKS}

[1] Morelli, N., 2019. Navigating Multiple Perspectives: DIASPORA Exit, Exile, Exodus At MAIIAM. [online] COBO Social. Available at: $<$ https://www.cobosocial.com/dossiers/navigating-multipleperspectives-diaspora-exit-exile-exodus-at-maiiam/> [Accessed 4 May 2019].

[2] Kandukuru, Nagarjun. 2019. "NOSTALGIC EAST AFRICA "MISCELLLANEOUS"". Sikh-Heritage.Co.Uk. http://www.sikh-

heritage.co.uk/heritage/sikhhert\%20EAfrica/Nostalgic\%20Mis cellaneous.html.

[3] Meisel, Abigail, and Chris Gash. 2017. "The Past, Present, And Future Of Human Migration". Omnia. https://omnia.sas.upenn.edu/story/past-present-and-futurehuman-migration.

[4] Dr. M. K. Gautam, Indian Diaspora: Ethnicity and Diasporic Identity, CARIM-India RR 2013/29, Robert Schuman Centre for Advanced Studies, San Domenico di Fiesole (FI): European University Institute, 2013.

\section{DOCUMENTARY}

[1] "Bridging words_Melting Pot- the story of Indian Diaspora.." Indian Diplomacy, Ministry of external Affairs and Government of India, Publisher, 3rd Sep, 2012, https://www.youtube.com/watch?v=0d2RoHwZTGs 